
\title{
СИСТЕМА ЗНАЧЕНИЙ ПОЛИСЕМАНТА БАШ «ГОЛОВА» В ТЮРКСКИХ ЯЗЫКАХ (НА МАТЕРИАЛЕ КУМЫКСКОГО ЯЗЫКА)
}

\section{HEAD BASH POLYEGANT VALUE SYSTEM IN TURKIC LANGUAGES (ON KUMYK LANGUAGE MATERIAL) \\ N. Gadzhiakhmedov B. Aselderova}

Summary: The work explores the process of emergence of new portable values motivated by the main value of a multivalued word in a polysemant. The most common values that combine the values of the multivalued word bash «head» are values that have an anthropocentric focus. In the semantic structure of the studied token are presented direct and real values. The analysis shows that there is both an immediate and an indirect relationship between the secondary values of the head bash polyemant and its basic value.

Keywords: multi-valued word, semantic structure, lexico-semantic variant, portable value, Turkic languages.
Гаджиахмедов Нурмагомед Эльдерханович

Д.ф.н., профессор, Дагестанский государственный университет (2. Махачкала) nur1@yandex.ru

Асельдерова Бурлият Джамаловна Дагестанский государственный университет (2. Махачкала) aselderova.b@mail.ru

Аннотация: В работе исследуется процесс возникновения в полисеманте баш «голова» новых переносных значений, мотивированных основным значением многозначного слова. Наиболее распространенными значениями, объединяющими значения многозначного слова баш «голова», являются значения, имеющие антропоцентрическую направленность. В семантической структуре исследуемой лексемы представлены прямое и переносные значения. Анализ показывает наличие как непосредственной, так и опосредованной связи вторичных значений полисеманта баш «голова» с его основным значением.

Ключевые слова: многозначное слово, семантическая структура, лексико-семантический вариант, переносное значение, тюркские языки.
A ктуальность определяется не только отсутствием специальных исследований, посвященных изучению семантической структуры отдельных лексем в кумыкском языкознании, но и необходимостью более глубокого изучения основного словарного фонда тюркских языков, выявления специфики развития семантической структуры лексических единиц, прослеживая историческое развитие многозначного слова.

Целью работы является выявление лексико-семантического объема полисеманта баш «голова» и установление функционально-семантических связей между основным и производными значениями.

Научная новизна статьи состоит в том, что это первый опыт организации семантической структуры и семантических отношений между лексико-семантическими вариантами субстантива баш «голова» и его производными лексическими единицами.

Лексема баш «голова» является общетюркским и в большинстве современных тюркских языков представлен именно этот фонетический вариант [2, с. 9; 6, с. 86-87].

При определении структурно-семантического потенциала субстантива баш «голова» мы пользовались словарями кумыкского языка $[1 ; 5]$. Однако необходимо отметить, что словари кумыкского языка на сегодняшний день не отражают все значения, реализуемые лексемой баш «голова». Поэтому для определения полного объема значений слова баш «голова» мы использовали свои собственные лексикографические разработки. В научный оборот вводится ряд значений полисеманта, которые словарями кумыкского языка не зафиксированы.

Лексема баш «голова»в современном кумыкском языке представлена следующими значениями:

1. голова человека или животного (башым авруй «голова болит», гамишни башы «голова буйвола»);

2. перен. человек, душа (при счете людей): Янгыз башым - тузсуз ашым (Поговорка). «Я одинок, поэтому не чувствую вкуса еды»;

3. перен. животное, штука: при счёте скота, поголовье (беш баш къара мал «пять голов крупного рогатого скота)»;

4. перен. глава, предводитель рода, тухума: (юртну башы «глава села»);

5. устар. супруг, муж: не яшы ёкъ, не башы ёкъ! «ни детей нет, ни мужа нет!»;

6. перен. сознание, ум, рассудок: башсыз адам «несознательный человек»;

7. перен. мысль: башы къырда «мысли на улице»;

8. перен. способность, талант, ум: яш башы булан «с детским умом»;

9. перен. начало // начальный, находящийся в начале (место локализации): орамны башында «в начале улицы»;

10. перен. верховье, исток (реки, ручья): Сулакъны ба- 
шында «в верховьях Сулака»;

11. перен. верхушка, вершина, гребень (горы, дерева): тереклени башлары «верхушки деревьев»;

12. перен. крыша: уьйню башын ябалар «делают крышу дома»;

13. перен. крышка; покрытие: къазанны башы «крышка кострюли»;

14. перен. голова; душа; человек: адам башына уьчер картоп «на человека три картошки»;

15. перен. заглавие, предисловие, глава (книги, романа): китапны баш сёзюнде «в предисловии книги»;

16. перен. конец, край: багъананы башына минмек «подняться на конец столба»;

17. перен. почетное место (за столом): шавхал столну башында олтургъан «князь сидит во главе стола»;

18. перен. изголовье (постели): Шамсутдин атасыны башлыгъында олтургъан. (И. Керимов). «Шамсутдин сидит у изголовья отца»;

19. перен. плоды растений, имеющие круглую или округленную форму; колос (зерна); головка (лука, чеснока); кочан (капусты); ботва (картофеля, моркови): бир баш согъан «головка лука»;

20. перен. утолщенная часть предмета: аркъалыкъны башы «начало (утолщенная часть) балки»;

21. перен. кусок (о сахаре): бир баш шекер «кусок сахаpa»;

22. перен. подушный: адам башына бир педире юзюм «на каждого по одному ведру винограда»;

23. перен. круглый пищевой продукт: бир баш бишлакъ «головка сыра»;

24. перен. первый, первенец: баш баласы «первенец»;

25. перен. причина (нарушения, беды): ярлылыкъны башы - эринчеклик (погов.). «причина бедности безделье»;

26. в определит. функ. перен.: верхний, находящийся наверху; на: башындагъы бёркю «папаха на голове»;

27. в опред. функ. перен. начальный (временное значение): баш сатыву «начало торговли»;

28. в опред. функ. перен. главный: юртну баш орамы «главная улица города»;

29. в послеложн. функц. в форме направит. п. башына «на голову»: башына папах гийген «надел на голову шапку»;

30. в послеложн. функ. в форме местн. п. башында «в начале чего-л.»: йылны башында «в начале года»;

31. в послеложн. функ. в форме исх. п. башындан «соотв. русскому предлогу с»: башындан аягъына ерли «с головы до ног».

Bсе названные значения полисеманта баш «голова» детерминированы историческим развитием семантической структуры слова.

Первые девять значений образуют семантическое ядро слова баш «голова», от которого берет свое начало основная часть значений, производных от баш «голова». Значения «голова», «глава» «вершина», «начало», «исток», «главный», «старший», «первый» встречаются уже в ранних памятниках тюркской письменности. Все они являются общетюркскими, как и большинство значений, образующих группы 1-9» $[6$, с. 60] .

Анализируя структуру данной лексемы, можно обнаружить целую сеть функционально-семантических связей и отношений между семемами многозначного слова.

В структурно-семантическом потенциале исследуемой лексемы считаем целесообразным выделить три блока значений:

1. чисто лексические (основные) значения слова баш, предназначенные для выполнения субстантивной функции;

2. определительные значения,

3. служебные послеложные функции лексемы баш.

Первый блок значений включает наряду с прямым значением ряд производных значений, образованных в результате различных типов переноса. В семантической парадигме слова баш в кумыкском языке можно выделить следующие значения:

1. Значения, имеющие антропоцентрическую направленность. Эти значения указывают:

1) на «часть тела человека или животного» и на значение «ум, сознание, рассудок»;

2) на зоонимическое значение, которое выражает единицу счета (скота);

3) на значения, связанные: а) с верхней частью предмета («утолщенная часть предмета», «вершина, верхушка, макушка, горы, деревьев и других предметов, имеющих высоту») и б) с передней частью предмета («начало», «заголовок», «почетное место (в комнате, за столом), «верховье, исток (реки, ручья)»).

Семантическое единство многозначного слова обнаруживается посредством определенной связи его основного значения со вторичными значениями. «Отдельные значения многозначного слова полностью, всем комплексом своих характеристик не пересекаются: возможно лишь совпадение отдельных составляющих этого комплекса» [8, с. 242].

Вторичные значения полисеманта связаны друг с другом с помощью общих семем или же они возникают на основе различных ассоциаций между отдельными предметами, явлениями, фактами, отражёнными в нашем сознании. Например, на основе антропонимического значения «человек» возникли вторичные значения, выражающие

1. человек, душа (при счете людей),

2. глава, предводитель (рода, тухума, клана, села, 
района), старший», стоящий выше других по служебному положению,

3. устар. супруг, муж,

4. сознание, ум, рассудок,

5. мысль, способность, талант,

6. ум, сознание, рассудок,

7. «душа» в количественном значении, когда слово баш «голова» указывает на количество членов семьи.

Со значением «толстый, утолщенная часть предмета» и «круглый» связаны такие вторичные значения слова баш «голова», как

1. головка,

2. утолщенная часть предмета (например, гвоздя, бревна и т.д.),

3. плоды растений, имеющие круглую форму.

Общим компонентом значений

а) «вершина, верхушка, макушка» (дерева, горы) и

б) «заголовок» являются значения «верхний», «верхняя часть предмета» и «начало чего-л.».

Значения «часть», «передний» объединяют три значения полисеманта -

а) «начало, передняя часть, перед»,

б) «верховье, исток (реки, ручья)»,

в) «почетное место».

Определительные значения слова баш «голова», представленные семами «главный» и «часть», объединяются значениями а) «центральный, головной», б) «заглавный» и в) «находящийся в верхней передней или начальной части чего-либо». А значения «находящийся в верхней передней или начальной части чего-либо» и «заглавный» связывают между собой семемы «передний» и «часть».

Семой «руководящий» объединены значения «старший по положению, возглавляющий что-либо» и «старший (стоящий выше других по знанию, по служебному положению)».

Таким образом, наиболее распространенными значениями, объединяющими значения многозначного слова баш, являются значения, имеющие антропоцентрическую направленность: «главный», «руководящий», «человек». В семантической структуре слова баш «голова» в кумыкском языке представлены прямое и переносные значения. Анализ показывает наличие как непосредственной, так и опосредованной связи вторичных значений полисеманта баш «голова» с его основным значением. Таким образом, полисемичность баш «голова» представляет смешанный тип многозначности, который в лингвистических исследованиях называется «радиально-цепочечной полисемией» $[4$, с. 11$]$.
Переносные значения образованы на базе основного значения, имеющего антропоцентрическую направленность. В переносных значениях может «хорошо осознаваться «внутренняя форма», связывающая их с прямыми значениями» [3, с. 116].

Метафорический перенос в значениях полисеманта баш «голова» можно обнаружить:

1) на основе сходства по форме:

а) «утолщенная или выступающая часть предмета, один из концов предмета, шляпка» (шурупну башы «головка шурупа», аркъалыкъны башы «утолщенный конец балки, бревна»);

б) «шарообразный плод некоторых растений» (бир баш согъан «головка лука»), бир баш хапуста «головка капусты);

в) «круглый пищевой продукт» (бир баш бишлакъ «одна головка сыра»);

г) «вершина, верхушка, макушка» (тавну башы // тав башы «вершина горы», терекни башы «макушка дерева»);

2) на основе сходства по местоположению:

а) «начало, передняя часть, перед» (юртну башы «начало села», оьзенни башы «начало реки»);

б) «заголовок» (макъаланы башы «заголовок статьи», кагъызны башы «начало письма»);

в) «верховье, исток (оьзенни башы «верховье реки», булакъны башы «исток родника»);

3) на основе сходства функций:

а) «старший по положению, возглавляющий чтолибо»: баш дохтур «главный врач», баш бухалмир «главный бухгалтер»;

б) «центральный, головной»: баш идарасы «главное учреждение», жумланы баш уьюрлери «главные члены предложения»;

в) «заглавный»: баш гъарп «заглавная буква».

Метонимический перенос характерен для значения «ум, сознание, рассудок»: бош баш «глупый», башы бар «умный».

Синекдоха является разновидностью метонимии. На синекдохе основаны следующие типы переноса значений:

а) «единица счета (скота)»: эллий баш къара мал «пятьдесят голов крупного рогатого скота»;

б) «душа (о человеке - обычно при указании количества членов семьи)»: уьч баш агьлю «семья из трех душ, из трех человек»;

в) «подушный»: адам башына уьч кило «три килограмма на душу населения»).

Расширение значений многозначного слова баш «голова» происходит чаще всего в процессе метафоризации, реже на основе метонимического переноса и синекдохи как разновидности метонимии. 
Слово баш «голова» кроме субстантивной выполняет еще и определительную функцию. Слово баш в определительной функции выражает значение «головной». Это значение состоит из нескольких семем:

1) значение «старший по положению, возглавляющий что-либо»;

В этой функции оно выражает следующие значения:

1) значения, связанные с соматонимом баш «голова»:

а) «то, что касается головы»,

б) «то, что предназначено для головы»;

2) пространственные значения:

а) «тот, кто находится в передней части чего-л.»;

б) «находящийся в центре»,

в) «заглавный, с большой буквы»;

3) значения, обозначающие руководителя: «старший по положению, званию, должности», «начальник», «генеральный»,

4) единица счета: «подушный».

Выступая в служебной послеложной функции слово баш «голова» выражает, прежде всего, пространственные значения. Средствами выражения этих значений являются пространственные падежи кумыкского языка - направительный, местный и предложный. В пространственных значениях лексемы баш «голова» можно определить следующую семантическую связь: баш в дательном падеже обозначает объект, к которому направлено действие (тавну башына «на вершину горы»), в местном падеже обозначает местоположение, местонахождение предмета (тавну башында «на вершине горы»), а в исходном падеже обозначает объект, от которого направлено действие (тавну башындан «с вершины горы»). Необходимо отметить и то, что в местном падеже функционально-семантических возможностей лексемы баш «голова» больше, чем в местном и исходном падежах: полисемант в местном падеже, наряду с функцией пространственной локализации, выражает еще временное значение (йылны башына «к началу учебного года»).

В значении времени (начало, сначала) полисемант баш «голова» употребляется и в обстоятельственной функции. В этой функции он используется с временными детерминантами вакъти «время, период», заман «время» и т.д. Баш вакътилерде партизанлар булагъа эркъатын деп турду (А. Гьамитов). «В первое время партизаны думали, что они муж с женой».

Как справедливо отмечает Э.В. Севортян «наиболее употребительные производные от баш «голова» лексические единицы, мотивированные тем или иным лексико-семантическим вариантом, «ничего существенного не вносят в его семантический спектр» [6, с. 87]. К ним относятся:

1) существительные на -лыкъ, имеющие во многих тюркских языках, а также в памятниках разные фонети- ческие модификации с разнообразными значениями («глава» «вожак», «царство» и др.). Среди субстантивов на -лыкъ отметим лексему башлыкъ, обозначающую известный головной убор в ряде тюркских языков, а также в русском, болгарском, сербском, польском языках [6, с. 87-88].

Можно легко установить семантическую соотносительность производящего слова и деривата в глагольной лексеме башла- «начинать»., репрезентирующей начинательный способ глагольного действия.

Одним из продуктивных аффиксов субстантивного словообразования в тюркских языках является аффикс -чы. Нередко производные полисеманта баш «голова» сами становятся полисемантами, образующими новые значения и являющимися производящей основой для новых слов. На базе исходного значения производящего слова баш с помощью аффикса -чы в тюркских языках образован полисемант башчы со значением «лицо по характеру занятий, действий или привычек» [7, с. 144]. Этот полисемант выражает следующие значения: 1.

1) глава, руководитель: районну башчысы «глава района»;

2) предводитель, вождь, вожак: къавумну башчысы «главарь племени»;

3) главарь, заправила, заводила, зачинщик, инициатор: ишни башчысы «инициатор дела»

2. главный, руководящий: башчы къатлавлар «руководящая прослойка».

Лексема башчы является производящей основой для полисеманта башчылыкъ, выражающего значения:

1) руководство, управление;

2) главенство, предводительство; гегемония.

От основы баш «голова» с помощью аффикса -сыз/сиз образовано прилагательное башсыз, являющееся полисемантом, выражающим отсутствие признака, названного мотивирующей основой. Слово имеет одно прямое и два переносных значения:

1) безголовый, не имеющий головы (напр. рыба в магазине)

2) перен. не имеющий главы, руководителя; оставшийся без присмотра, безнадзорный

3) перен. глупый, бестолковый, тупой.

Лексема башлы, образованное от основы баш при помощи аффикса -лы, также является полисемантом:

1. -главый, -головый;

2. с числ. означает количество.

В словообразовательном гнезде с вершиной баш «голова» имеет место немало производных полисемантов, развивших новые значения, в которых в отдельных случаях сложно усмотреть связь с тем или иным значением 


\section{слова баш «голова».}

Итак, семантическая структура слова баш «голова» может быть представлена следующим образом. В центральную часть этимолого-семантического поля входят значения, имеющие антропоцентрическую направленность - голова как жизненно важный орган человека» (основное значение). Далее идет ряд производных значений, образованных путем метафори- ческого осмысления основного значения. Семантическая структура слова баш «голова» включает в себя не только субстантивную, но и адъективную и обстоятельственную функции, ряд самостоятельных семем с разными оттенками. В адъективной функции баш «голова» выражает значительно меньше значений, чем в субстантивной функции, а в обстоятельственной функции реализует только обстоятельственное и временное значения.

\section{ЛИТЕРАТУРА}

1. Бамматов Б.Г., Гаджиахмедов Н.Э. Кумыкско-русский словарь. - Магьачкъала: ИЯЛИ ДНЦ РАН, 2013. — 523 с.

2. Дмитриев Н.К. 0 тюркских элементах русского словаря // Лексикографический сборник. Вып. III. — М., 1958. — С. 3 - 47

3. Кузнецова Э.В. Лексикология русского языка. Учебное пособие для филологических факультетов университетов. - М.: Высшая школа, 1989. - 216 c.

4. Ненилина Н.Г. Полисемант голова и реализация его словообразовательного потенциала в русском литературном языке и народных говорах: автореф. дис. ... канд. филол. наук. — Белгород, 2006. — 23 с.

5. Русско-кумыкский словарь. Под ред. Б.Г. Бамматова. — Махачкала: Дагестанский научный центр РАН, 1997. — 1754 с.

6. Севортян Э.В. Этимологический словарь тюркских языков: Общетюркские и межтюркские основы на букву «Б». — М., 1978. — 349 с.

7. Сравнительно-историческая грамматика тюркских языков. Морфология. - М.: Наука, 1988. — 560 c.

8. Шведова Н.Ю. Три заметки о смысловых пересечениях // Сокровенные смыслы: Слово. Текст. Культура. М.: Языки славянской культуры, 2004. С. $242-254$.

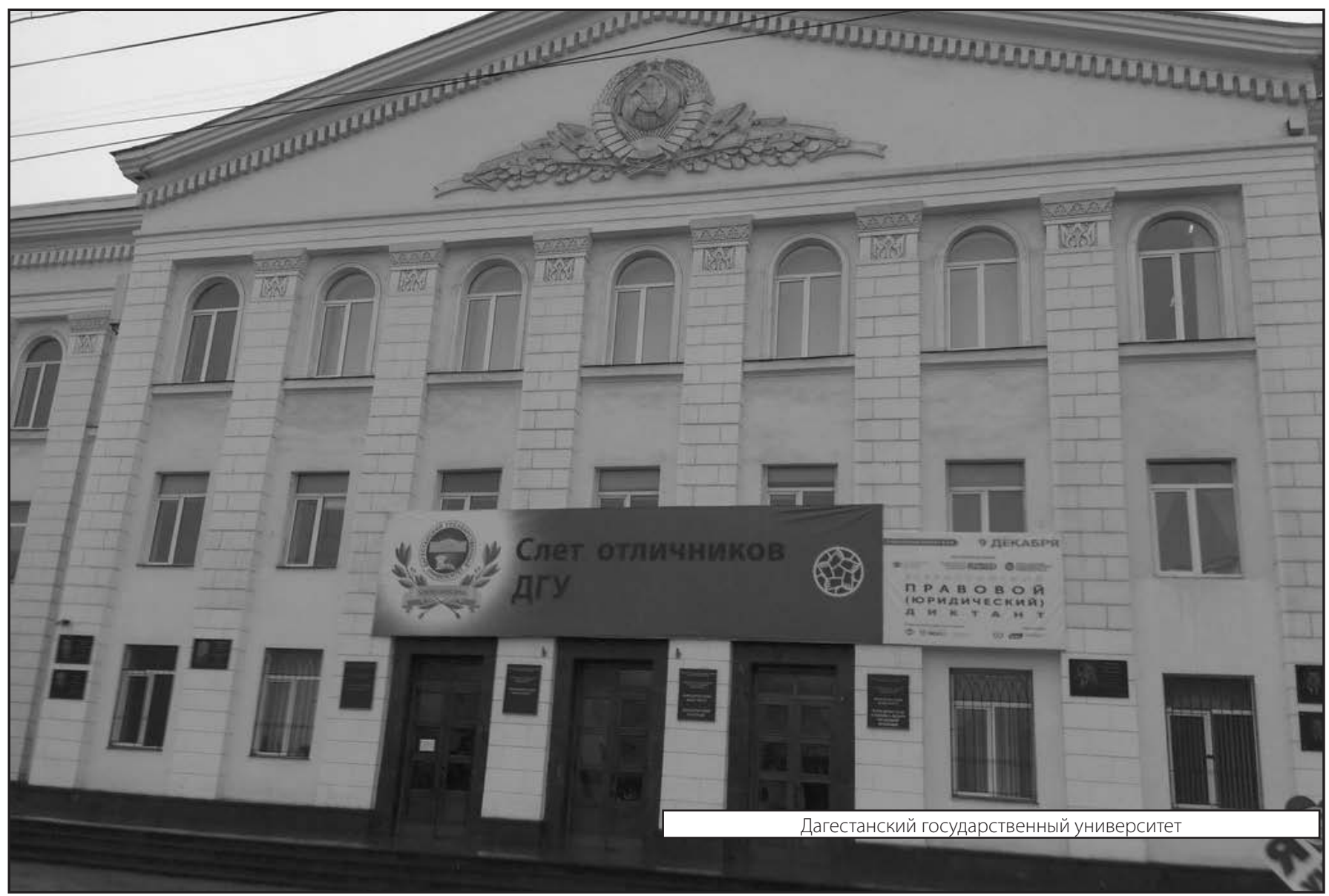

